\title{
Síndrome de Jó ou hiperimunoglobulinemia E*
}

\author{
Ricardo Coelho Reis ${ }^{1}$, Marcelo Alcântara Holanda ${ }^{2}$, JuvÊncio Paiva CÂmara ${ }^{3}$, \\ José Humberto AraúuO ${ }^{4}$, Micheline Paiva AquinO ${ }^{5}$, LaRyssa Braga CAVAlCANTE SANTANA ${ }^{5}$
}

\begin{abstract}
A síndrome de Jó ou hiperimunoglobulinemia E é uma rara condição de imunodeficiência, sem etiologia definida, caracterizada por infecções de repetição dos tratos respiratórios superior e inferior e da pele associadas a níveis elevados de imunoglobulina $\mathrm{E}$, eosinofilia e alterações faciais peculiares. Relata-se o caso de um homem de 22 anos, portador da doença, complicada com empiema pleural e cistos pulmonares e boa evolução. (J Pneumol 2001;27(2):115-118)
\end{abstract}

\section{Job's syndrome or hyperimmunoglobulinemia $E$}

Job's syndrome, or hyperimmunoglobulinemia $E$, is a rare immunodeficiency condition with no established etiology, characterized by recurrent lower and upper respiratory tract and skin infections associated with high levels of immunoglobulin E, eosinophilia, and a characteristic facial alteration. The authors report on a 22-year-old man who carried this disease complicated by pleural empyema and lung cysts, showing a good evolution.

Descritores - Síndrome de Jó. Infecções respiratórias. Recidiva.

Key words - Job's syndrome. Respiratory tract infections. Recurrence.

\section{INTRODUÇÃO}

Desde a descrição dos primeiros casos da doença, em $1966^{(1)}$, o comprometimento do sistema respiratório tem importância fundamental na síndrome de Jó, uma rara condição também conhecida como síndrome hiper-IgE, atualmente enquadrada no grupo das imunodeficiências hereditárias que ainda guarda diversos aspectos obscuros no tocante à sua fisiopatologia, evolução e prognóstico.

* Trabalho realizado no Serviço de Pneumologia do Hospital de Messejana, Fortaleza, CE.

1. Médico residente do $2^{0}$ ano de Pneumologia.

2. Doutor em Pneumologia, Universidade Federal de São Paulo (Unifesp); Coordenador da Residência de Pneumologia do Hospital de Messejana, Fortaleza, CE.

3. Médico Assistente do Serviço de Pneumologia.

4. Médico do Hospital Regional de Iguatu, CE.

5. Médica residente.

Endereço para correspondência - Ricardo Coelho Reis, Rua Tenente Wilson, 154 - 60850-810 - Fortaleza, CE. Tels. (85) 272-2803/91069810; E-mail: sibilo@bol.com.br

Recebido para publicação em 20/6/00. Aprovado, após revisão, em 25/8/00.
Siglas e abreviaturas utilizadas neste trabalho

IgE - Imunoglobulina E

HTE - Hemitórax esquerdo

HIV - Vírus da imunodeficiência humana

LDH - Desidrogenase láctica

DNBT - Dinitro azul tetrazólio

A despeito do número reduzido de casos catalogados e da falta de descrição de um seguimento prolongado dos pacientes, o pronto reconhecimento e correção das complicações pleuropulmonares continuam sendo um dos principais recursos no manuseio dessa doença, diminuindo de forma significativa sua mortalidade.

\section{RELATO DO CASO}

Homem, 22 anos, pardo, agricultor, sadio até cinco meses da admissão, quando notou aparecimento de furúnculos na região mandibular direita e no membro inferior direito, tendo feito uso de penicilina benzatina, com regressão total das lesões. Um mês após o quadro inicial evoluiu com tosse associada a broncorréia purulenta, febre alta, hemoptóicos e dor pleurítica bilateral. A radiografia do tórax revelava múltiplas opacidades de padrão alveolar no lobo superior direito e lobos superior e inferior esquerdos. Foi submetido a tratamento com oxacilina e gentamicina em regime hospitalar por 15 dias, tendo recebido alta assintomático. Após esse episódio apresentou três novos internamentos, sempre com mesmo 


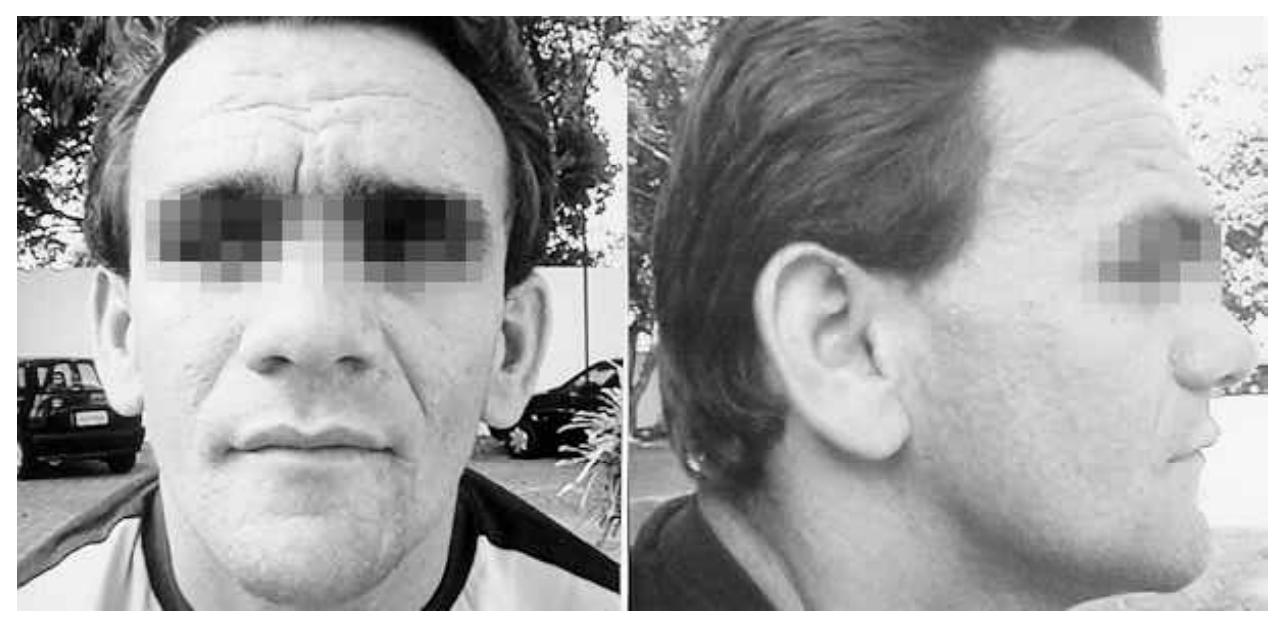

Figura 1 - Vista frontal e em perfil do paciente: notar a proeminência da região frontal, o alargamento da base do nariz e o rash eczematóide característicos da "face do Jó".

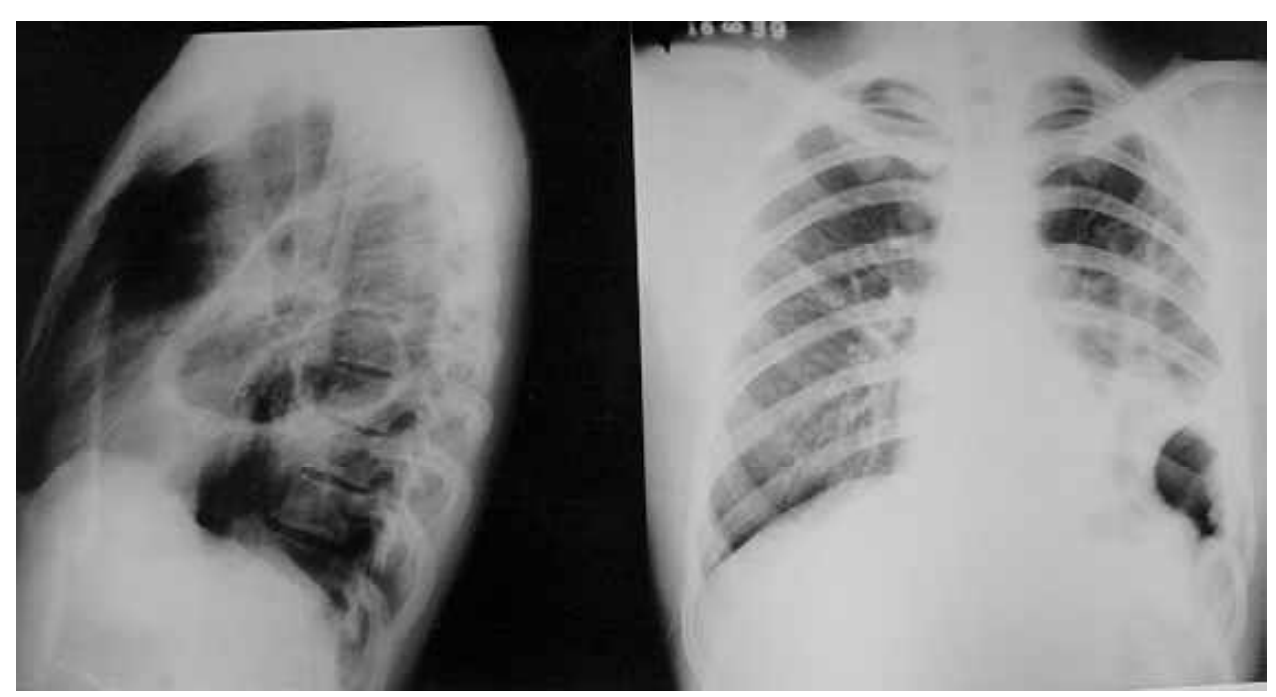

Figura 2 - Radiografia de tórax em PA e perfil esquerdo: empiema crônico em base do HTE e cistos pulmonares remanescentes.

quadro clínico e radiológico, permanecendo assintomático por um período que variava de duas a quatro semanas. Por ocasião da última internação, 15 dias antes da admissão, apresentou piora do estado geral e surgimento de dispnéia e vômitos, tendo a investigação radiológica revelado nível hidroaéreo em lobo inferior esquerdo, que rapidamente evoluiu para velamento dos dois terços inferiores do HTE. Foi então submetido à drenagem torácica fechada e encaminhado ao nosso serviço.

Paciente referia um episódio de furunculose aos dez anos e um episódio de pneumonia aos 12 anos. Sem história de alergias, etilismo ou tabagismo e sem sintomatologia semelhante à sua em qualquer membro da família. Não havia história ocupacional relevante.
Apresentava-se em regular estado geral, eupnéico, febril $\left(38^{\circ} \mathrm{C}\right)$, consciente, normotenso. Notava-se face com a região frontal e a arcada supra-orbital proeminentes e a base do nariz alargada (Figura 1). Semiologia cardíaca normal. Ausculta pulmonar com murmúrio diminuído em base esquerda. Dreno torácico em selo d'água funcionante com líquido turvo, sanguinolento. Sem artrites ou baqueteamento digital. Na admissão, o hemograma evidenciava marcada leucocitose $\left(25.700 / \mathrm{mm}^{3}\right)$ e eosinofilia importante (11\%), sendo o perfil imunológico mostrado na Tabela 1. A análise do líquido pleural mostrava a bioquímica com $\mathrm{pH}=7,34$, albumina $=2,4 \mathrm{~g} / \mathrm{dl}$, LDH $=$ $7.428 \mathrm{U} / \mathrm{l}$, glicose $=43 \mathrm{mg} / \mathrm{dl}$ e a citologia com 198 células (neutrófilos $=90 \%$, linfócitos $=5 \%$, macrófagos $=$ 
TABELA 1

Valores laboratoriais imunológicos

\begin{tabular}{cc}
\hline \multicolumn{1}{c}{ Variáveis } & Admissão \\
\hline Imunoglobulinas $(\mathrm{mg} / \mathrm{dl})$ & \\
$\lg \mathrm{I}$ & 2.20 \\
$\lg \mathrm{IgE}(\mathrm{IU} / \mathrm{ml})$ & 2.360 \\
$\lg M$ & 2.000 \\
Complemento $(\mathrm{mg} / \mathrm{dl})$ & 177 \\
$\mathrm{C}_{3}$ & 234 \\
$\mathrm{C}_{4}$ & 40,7 \\
$\mathrm{CH}-50(\mathrm{UH})$ & 290 \\
\hline Anti-HIV $($ ELISA) & negativo \\
\hline
\end{tabular}

5\%). As culturas de sangue e do líquido pleural foram negativas, bem como a bacterioscopia do escarro e a pesquisa de parasitas nas fezes em três amostras. As radiografias dos seios da face e do crânio foram normais, assim como o ecocardiograma. Foram realizados ainda teste cutâneo intradérmico para os principais alérgenos inalatórios que foi negativo e teste de DNBT para avaliação da capacidade fagocitária dos neutrófilos que resultou normal.

O paciente evoluiu, após introdução de vancomicina, com desaparecimento da febre, da tosse e da dispnéia, sendo retirado o dreno torácico no sexto dia de internamento. Persistiu, porém, com dor tipo pleurítica em HTE e radiografia compativel com empiema crônico e presença de cistos pulmonares à esquerda (Figura 2), sendo submetido à pleurostomia em base esquerda.

Recebeu alta após quatro semanas de antibioticoterapia com completa resolução do quadro pleural. Durante controle radiológico, em sua última visita ambulatorial, 11 meses após o internamento, apresentava-se sem qualquer sinal ou sintoma de infecção, com total involução dos cistos pulmonares.

\section{DISCUSSÃO}

O extenso comprometimento cutâneo por infecções piogênicas recorrentes encontrado nos primeiros casos relatados por Davis et al. ${ }^{(1)}$ foi o que o inspirou a denominar a síndrome, numa alusão ao conhecido personagem bíblico Jó, que, entre outras provações de sua paciência e amor a Deus, teve o corpo recoberto por pústulas ${ }^{(2)}$.

Atualmente, o difícil manuseio dos pacientes com a síndrome de hiperimunoglobulina $\mathrm{E}$ está mais associado à dificuldade no estabelecimento de uma base fisiopatológica e terapêutica específica que propriamente no reconhecimento de suas manifestações clínicas.
O diagnóstico é estabelecido e deve ser sempre lembrado na presença de infecções de repetição dos tratos respiratórios superior e inferior e da pele, iniciando-se mais comumente ao nascimento ou na infância, associadas a níveis séricos de IgE pelo menos dez vezes maiores que o limite superior da normalidade $(>2.000 \mathrm{UI} / \mathrm{ml})^{(3)}$. Outros achados freqüentes incluem eosinofilia periférica ${ }^{(4)}$, rash eczematóide ${ }^{(2,5)}$, candidíase cutânea ${ }^{(5)}$, alterações dentárias e ósseas ${ }^{(5)}$ e, mais raramente, ceratoconjuntivite $e^{(2)}$.

Atualmente, admite-se um conjunto de alterações craniofaciais, com destaque para a proeminência da fronte $e$ do arco superciliar e alargamento da base do nariz, dando um aspecto grosseiro ao rosto, conhecido como "face de Jó”(6).

Não há predominância de sexo ou raça ${ }^{(2)}$, tendo sido identificado um padrão de transmissão autossômica dominante, porém com expressão variável(5).

As anormalidades encontradas sugerem um defeito funcional dos neutrófilos, mais precisamente em sua quimiotaxia, já que a capacidade fagocitária é normal ${ }^{(3,7)}$. Esse déficit de quimioatração seria secundário à disfunção de um grupo de linfócitos T, que também estariam associados à sintese anormal de anticorpos e citocinas ${ }^{(3,5,7)}$. Tais achados não são constantes nem guardam relação com a propensão às infecções ${ }^{(3,8)}$, ficando a síndrome ainda sem etiologia definida.

Passados 34 anos desde a sua primeira descrição, a doença ainda não apresenta um tratamento específico curativo. Drogas como ácido ascórbico, levamisol, cimetidina e fator de transferência que melhoraram in vitro a quimiotaxia dos neutrófilos ${ }^{(2,3,7)}$ não se mostraram eficazes na prevenção das infecções recorrentes. Gama-globulina, plasmaférese $e^{(2,7)} e$, mais recentemente, ciclosporina $A^{(9,10)}$ são opções promissoras que parecem atuar na imunorregulação dos linfócitos, mas que ainda carecem de estudos mais prolongados. Diante disso, a melhor abordagem continua baseando-se no tratamento precoce $e$ na profilaxia prolongada das infecções de repetição.

A intervenção cirúrgica é essencial na drenagem dos abscessos cutâneos e empiemas pleurais.

No seguimento dos pacientes, especial atenção deve ser dada aos cistos pulmonares adquiridos decorrentes das pneumonias de repetição. Nos casos em que estes permanecem cronicamente infectados por bactérias saprofíticas e fungos ${ }^{(12)}$, a ressecção cirúrgica está indicada.

\section{REFERÊNCIAS}

1. Davis SD, Schaller J, Wedgwood RJ. Job's syndrome: recurrent, "cold", staphylococcal abscesses. Lancet 1966;1:1013-1015.

2. Leung DY, Geha RS. Clinical and immunologic aspects of the hyperimmunoglobulin E syndrome. Hematol Oncol Clin North Am 1988;2 91-100. 
3. Donabedian H, Gallin JI. The hyperimmunoglobulin E recurrent-infection (Job's) syndrome: a review of the $\mathrm{NIH}$ experience and the literature. Medicine (Baltimore) 1983;62:195-208.

4. Buckley RH, Wray BB, Belmaker EZ. Extreme hyperimmunoglobulinemia E and undue susceptibility to infection. Pediatrics 1972;49. 59-70.

5. Grimbacher B, Holland SM, Gallin JI, et al. Hyper-IgE syndrome with recurrent infections an autosomal dominant multisystem disorder. $\mathrm{N}$ Engl J Med 1999;340:692-702.

6. Borges WG, Hensley T, Carey JC, Petrak BA, Hill HR. The face of Job. J Pediatr 1998;133:303-305.

7. Salaria M, Singh S, Kumar L. Hyperimmunoglobulin E syndrome. Indian Pediatr 1997;34:827-829.

8. Blum R, Geller G, Fish LA. Recurrent severe staphylococcal infections, eczematoid rash, extreme elevations of IgE, eosinophilia and divergent chemotactic responses in two generations. J Pediatr 1977; 90:607-609.

9. Wolach B, Eliakim A, Pomeranz A, Cohen AH, Nusbacher J, Metzker A. Cyclosporin treatment of hyperimmunoglobulin E syndrome. Lancet 1996;347:367.

10. Etzioni A, Shehadeh N, Brecher A, Yorman S, Pollack S. Cyclosporin A in hyperimmunoglobulin E syndrome. Ann Allergy Asthma Immunol 1997; 78:413-414.

11. Cooper MD, Lawton III AR. Primary immune deficiency diseases. In: Fauci AS, Braunwald E, Isselbacher KJ, et al, eds. Principles of internal medicine. 14th ed. New York: McGraw-Hill, 1998;307:1790.

12. Merten DF, Buckley RH, Pratt PC, Effmann EL, Grossman H. Hyperimmunoglobulinemia E syndrome: radiographic observations. Radiology $1979 ; 132: 71-78$. 